Session No: 3425

\title{
THE DEVELOPMENT OF COMMUNICATION AND DESIGN SKILLS THROUGH MULTI-DISCIPLINARY TEAMWORKING
}

\author{
M. D. Bramhall, R. G. Harris, D. Hick, I. M. Robinson \\ Sheffield Hallam University, Faculty of Arts, Computing, Engineering and \\ Sciences, Sheffield, UK
}

\begin{abstract}
This paper details the methodologies developed at Sheffield Hallam University for improving students' design, teamworking and communication skills through participation in undergraduate and postgraduate modules. One module is a residential 'teamwork and leadership course', which final year undergraduates undertake. This module develops the students' teamwork and leadership skills away from the university, by participating in a series of indoor and outdoor tasks, with an inter-disciplinary design focus, spread over a weekend. Assessment is by both staff observation and student self-reflection with a 'portfolio style' evidence-based final report. The second module described in this paper uses 'video conferencing' between higher education institutions, with postgraduate students at each university undertaking joint project work. These joint projects are multi-disciplinary, for example engineering students working with business students, or materials engineering students working with design students. This leads to the students' greater understanding of the importance of teambuilding within a multi-disciplinary environment. The paper evidences evaluation of the modules described, incorporating both students' and the United Kingdom (UK) engineering professional bodies' views on the skills and expertise that they have developed, and the importance that they perceive of this skill development for a professional engineer in the UK.
\end{abstract}

\section{Introduction}

The needs of UK industry are constantly changing, moving towards highly specialised, high quality manufacturing within a globally competitive market place. Engineers more than ever need to be equipped not only with the necessary specialist technical skills, but also have excellent innovative, design, communication, IT, teamwork and inter-disciplinary skills if industry is to maintain any competitive advantage. Many UK industries are now 'out-sourcing' their manufacturing to cheaper labour markets within Eastern Europe. Graduate engineers need to be able to communicate and work with these European countries. They need to have the wider skills outlined above to be able to succeed in this demanding global marketplace. Richardson [1] tells us that:

\footnotetext{
"traditionally engineers and scientists in the UK have seen themselves only as inventors or creators of systems and have left businessmen to worry about the possibility of their commercial exploitation". 
Thus there is now a need for a shift in the mindset of engineers, from seeing themselves as just 'engineers', to being people who have a well-rounded understanding of, and an ability to make decisions within, the commercial environment. They must be businessmen and businesswomen as well as inventors and creators, with good teamwork and communication skills. It is logical then, that if our businesses need a different type of engineer, then these 'new' skills must be fostered, developed and learned by our engineering students.

In the past, organisations tended to recruit from traditional universities, using the 'knowledge base' of the student as evidence that graduates could undertake tasks in a "compliant, dutiful and reliable manner" [2]. However, in the context of the changing nature of the engineering industry, the graduates of the new millennium are required to be equipped with skills to accommodate these changes. Indeed graduates will have:

"increasingly flexible and truncated careers. Hence graduates have to be more 'flexible' in their attitudes towards work and more 'adaptive' in their behaviour in the labour market. They require a broader portfolio of technical, social and personal skills than...were emphasised in the past." $[2]$.

Therefore, the type of graduates we need to produce are those, not only with engineering skills but ones that are business-aware, with good professional and personal skills. However, the lack of links between university and industry means that we don't always produce the type of graduates that industry really requires. And, in fact, we have been slow to respond.

Engineering students themselves want to study a wider curriculum. There has been a growth in the UK of more technology-based degrees that cover wider aspects of business and industry. Students want to see more business, finance, marketing, IT, as well as interpersonal skills such as negotiating skills in the curriculum [3].

The UK Engineering Council, in its 3rd Edition of Standards and routes to Registration (SARTOR) [4], continued with the accelerating trend of basing the curriculum within the vocational arena, and argued that engineering courses must give:

"greater breadth and depth of coverage, to meet the needs of industry in...management and business topics and personal skills..."

The tone of SARTOR marked a significant change in the level of control governmental bodies now have over the HE institutions. These were very specific guidelines about exactly what a course should include:

"...an awareness of quality systems in engineering; requirements and responsibilities of leadership; obligations to work safely and to apply safe systems of work; risk analysis; the financial, economic, social and environmental factors of significance to engineering; the relevant legal, statutory and contractual obligations and the broader obligations of engineers in society"[4]. 
SARTOR has since been replaced by the UK Standard for Engineering Professional Competence (UK-SPEC) on $1^{\text {st }}$ March 2004 [5]. In this it is stated that:

"Chartered Engineers are characterised by their ability to develop appropriate solutions to engineering problems, using new or existing technologies, through innovation, creativity and change. They might develop and apply new technologies, promote advanced designs and design methods, introduce new and more efficient production techniques, marketing and construction concepts, pioneer new engineering services and management methods. Chartered Engineers are variously engaged in technical and commercial leadership and possess effective interpersonal skills."

Both SARTOR and now UK-SPEC require that engineers must study at postgraduate level in order to achieve professional engineer 'Chartered' status. They must study in greater depth for their specialist chosen career, have greater breadth of technical knowledge and study business and management. Postgraduate engineering courses that meet these requirements must also have a team-based multi-disciplinary project so that graduate engineers have the experience of working within a team. They are therefore developing teamwork, communication and leadership skills.

\section{UK higher education for engineers}

Higher education institutions need therefore to develop their undergraduate and postgraduate engineering courses to equip these students with the necessary knowledge and skills for them to be competitive in the market place and achieve their professional status.

The educational base for graduates to become chartered engineers starts with their first (Bachelors) degree, which can be either 3 years full time or 4 years sandwich, where students are placed in industry usually in their third year, returning to complete their final year (year 4). These courses must be accredited by the appropriate professional body, such as the Institution of Mechanical Engineers (IMechE). To complete their educational base, graduates from these courses have to undertake study at Masters level and complete an approved MSc for their 'advanced learning' component [5]. This component should include technical deepening; broadening - both technical and non-technical, including finance and marketing knowledge and skills; and a group project to develop personal and professional skills. Courses at Sheffield Hallam University have strived to include these components at Masters level, with underpinning elements at Bachelors level. In the following sections two such areas are discussed that show how students are developed at Sheffield Hallam - a 'Teamwork and Leadership' module at final year undergraduate level, and a module 'International Product Development' at postgraduate level.

\section{Teamwork and leadership module}

A leadership module was developed several years ago as a residential 'outward bound' week offsite for the Integrated Engineering Degree Programme [6, 7]. This has since evolved into a 'Teamwork and Leadership' optional module within the Sheffield Hallam final year undergraduate engineering programme. Some fifty students opt to undertake this module each 
year. Students see the need of developing these skills for their future careers as engineers and hence the course is becoming a popular option. A major element of this module involves a number of staff taking the engineering undergraduates on a residential course lasting a full weekend. Students are introduced to the principles of teamwork and leadership during keynote lectures, seminars and exercises prior to the residential. Students are given, for example, a Belbin questionnaire [8] so that they can analyse themselves in terms of their major strengths and roles that they have within a team situation. They then undertake a series of formative tasks in teams to develop skills and an evidence base for their development. The students are split, based on the Belbin analysis, into teams. They are then given the task of designing an engineering artefact to a certain specification. Artefacts used have included small bridges and self-propelled vehicles.

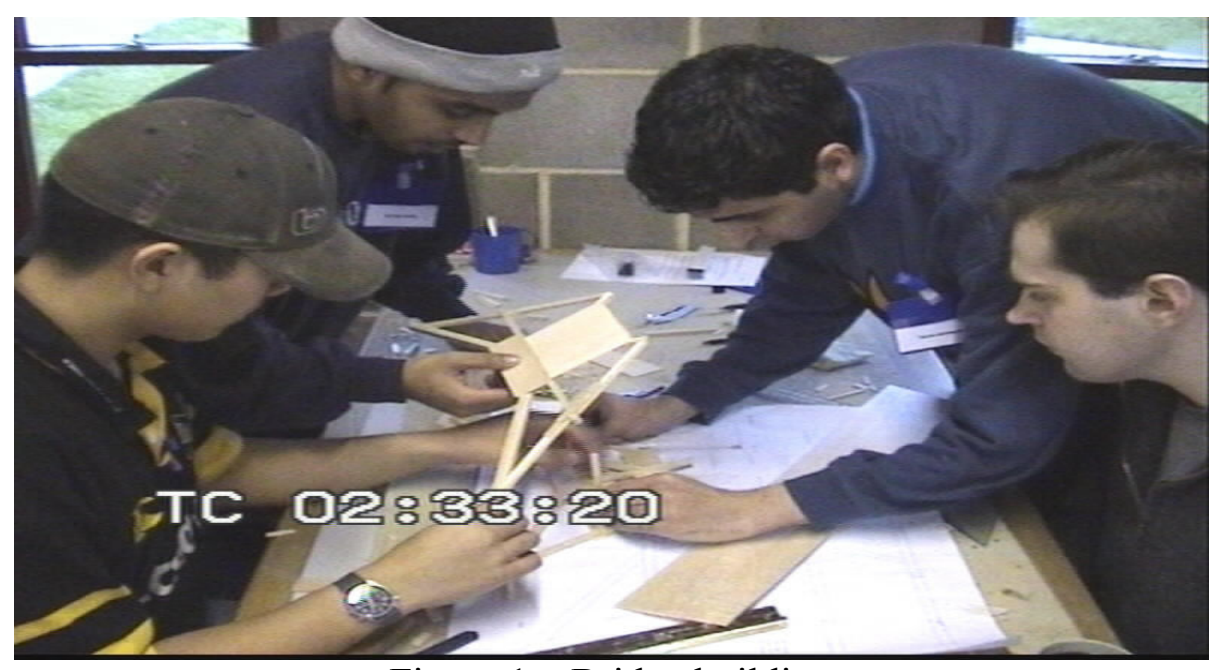

Figure 1 - Bridge building

Students have to meet in their teams prior to the residential course, so that they can initiate their design. They must have meetings that are minuted for evidence and progress. The artefact is then built during the residential course, Figure1. 


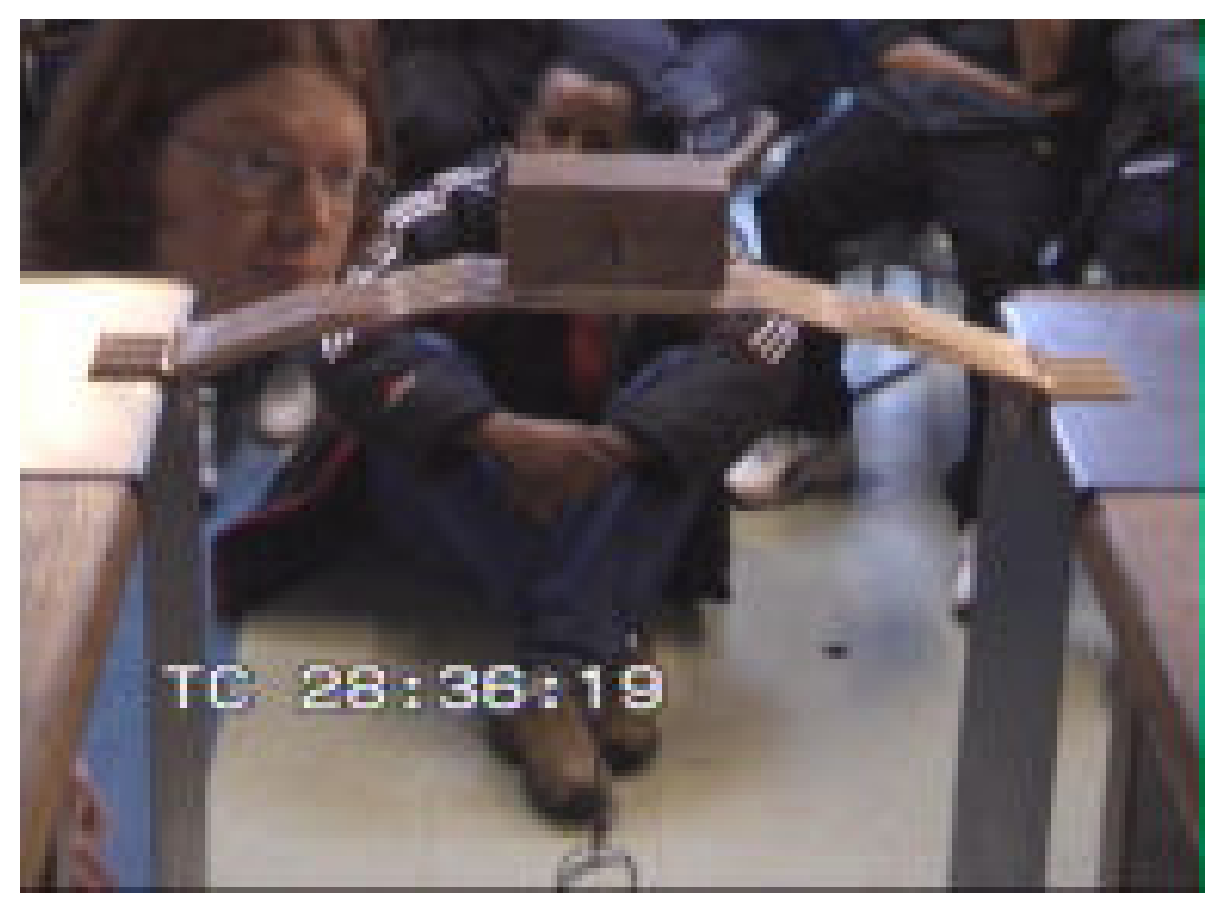

Figure 2 - Bridge testing

The exercise is competitive, for example, students would be in competition to build the bridge that sustains the highest strength to weight ratio. Testing the bridges to destruction is a highlight of the weekend, Figure 2. In addition, during the residential course, the students undertake a series of indoor and outdoor exercises that help them further develop, Figure 3.

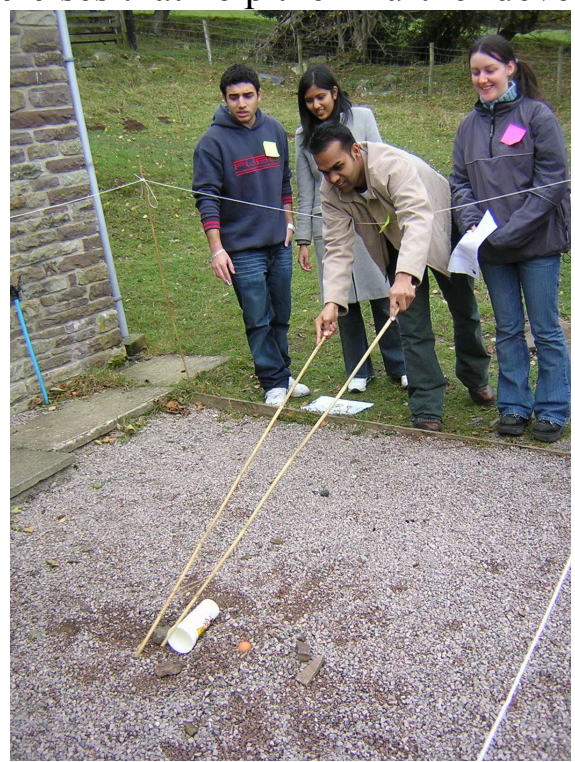

Figure 3-Outdoor team exercise- 'Cone Retrieval'

Self-reflection after each exercise is an important part of the course as it helps them to identify personal strengths and areas for development. At the end of the course the students undertake a formal team presentation. The main objective of this presentation is for them to communicate their design development, how they worked as a team and what skills they have developed 
within the module. Assessment of the module is made up of a self-reflective critical report with a portfolio of evidence, a group report on the bridge design and the final presentation.

\section{Video conferencing}

A recent development with engineering students has seen the use of Video Conferencing as a tool to aid the augmentation of communication and teamworking skills, see Figure 4.

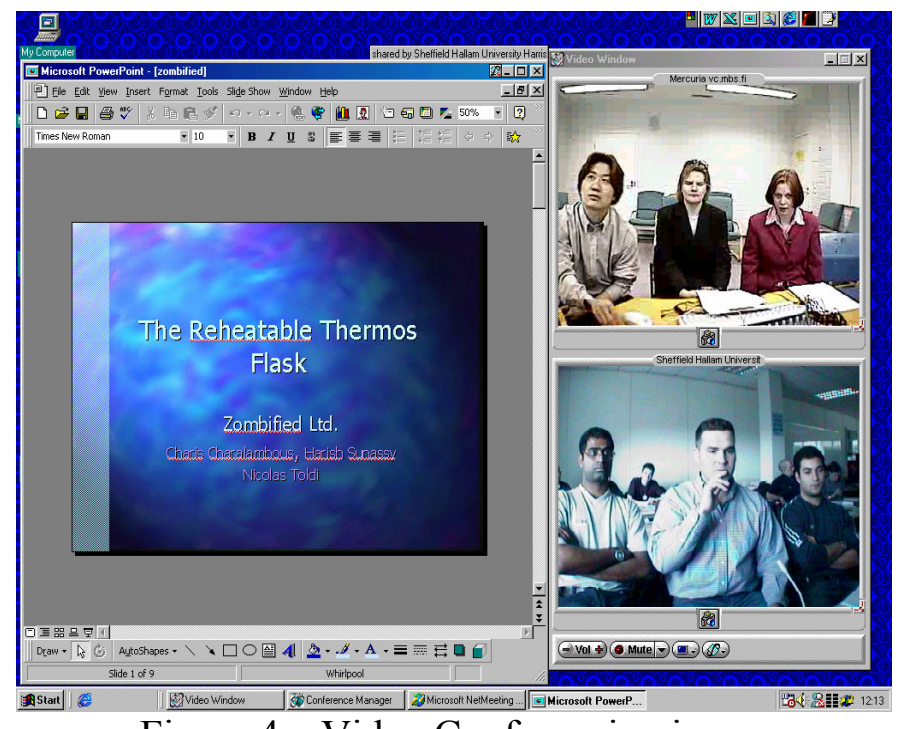

Figure 4 - Video Conferencing in use

This has involved higher education institutions across Europe with groups of postgraduate students working in cross-disciplinary teams spanning different countries using 'International Product Development' as a main theme [9]. International Product Development is a core postgraduate module on Sheffield Hallam's engineering postgraduate programme. MSc students are required to develop a concept design for a new product whilst working with their counterparts in another country. One scenario has been Sheffield-based engineering postgraduates working with business studies students in Helsinki. The skills and knowledge developed include:

- Communication skills

- Teamworking skills

- Leadership skills

- Project management

- Marketing

- Finance

- Design

- Manufacturing skills

- Specialist engineering knowledge 


\section{International Product Development - Group Work Case Study}

Sheffield Hallam University, UK: postgraduate engineering students

Mercuria Business School, Helsinki, Finland: postgraduate business students

Product: Re-heatable thermos flask made out of bio-degradable polymers

Students communicated weekly through video conferencing, in order to develop the concept design, manufacturing, materials, financial and marketing aspects of the product.

The recommended use of bio-degradable materials helps students to consider engineering design for sustainability, a key current topic.

Working across European higher education institutions enables students to gain awareness and understanding of the cultural differences between the two countries, which is an important asset to both sets of students who will end up working in a global marketplace.

The final project presentation was jointly presented using PowerPoint across the internet (Figure 4)

Curtis [10] states that too many products fail because they are either product or market driven. He discusses that a holistic view must be taken and that engineers can do this by developing marketing skills to complement their design capabilities.

A recent development for the concept design has been to theme the student projects. This year, for example, the students' designed products had to be based on bio-degradable polymers.(See above case study). A bio-degradable polymer manufacturer was invited to give a keynote presentation to the students, who were then able to discuss their designs with the industrialist.

This type of group-based project work is also exactly what SARTOR 3 and its 'matching sections' required at postgraduate level for an accredited, chartered engineering course [4]. Sheffield Hallam attracted Engineering and Physical Sciences Research Council (EPSRC) funding to develop the 'International Product Development' module for its MSc programme that involved group teamworking in a multi-disciplinary environment [11].

A further development of the use of video conferencing was gained through a Higher Education Funding Council for England (HEFCE) grant - Funding Development in Teaching and Learning (FDTL). Led by Imperial College, London, this grant has funded the development of innovative 'Tutorials in Materials'. Sheffield Hallam is one of the partners. During the last year the use of video conferencing has therefore been extended to a Materials Engineering undergraduate course where materials students in Sheffield work with Design students at The Robert Gordon University in Aberdeen. The scenario for this joint project work was for the students to design a new product, or develop an existing one by using advanced composite materials. Communication 
between teams was by a weekly 20 minute video conference between sites. In addition the students were able to telephone, email, or fax each other. The materials students not only developed their teamworking skills by video conferencing between sites, but also have developed their design skills. The design students on the other hand also gained a great deal of knowledge from the materials students about the properties and applications of composites, and the factors affecting their manufacture.

Assessment of the module involves a final group report and group presentation, individual weekly oral reports on progress, and a final individual critical review.

\section{Evaluation - Student views}

Student views were identified through their individual self-critical evaluation that they all undertake. In addition they complete an end of module questionnaire and several students have been interviewed. Their comments reveal the student view of this type of project and its benefits:

On the 'teamwork and leadership' course:

'...This module has been the best one in my final year. I wish we had done it earlier in the course...'

‘...I now understand how a good team works and about the different roles in a team...'

'...I was apprehensive about this course at first, but in the end I really enjoyed it'

'...important to have a good degree of communication for successful completion of a project.'

‘...the skills we have developed will help us when we go for job interviews...'

'...gave us valuable experiences that could not be taught in the classroom..'

On video conferencing:

'...I found this experience very enlightening and an excellent communication tool when distance constraints mean that the two parties don't have the possibility of meeting in person....'

'..The idea of linking up with colleagues from another university was brilliant and exciting...'

'...I feel this has inspired me to further my education, and has also made me feel confident and receptive to learning....'

'...work with Design students in Aberdeen greatly improved with the introduction of video conferencing..'

'....Due to my experience I would like to recommend that more of these courses are arranged to give other people the opportunity to discover abilities that are hidden beneath the surface...' 
However, many students felt that they did not gain as much as they could have from the other students in the participating university:

'... as a group we never received any answers to our specific questions, and were required to answer them ourselves. We therefore lost potentially valuable feedback on our project...'

' .....The concept of our group and discussions being linked to the other university initially appeared constructive in terms of valuable feedback........however I felt the feedback during the video conferencing could have been more direct and tailored to our product...'

\section{Evaluation - Tutor views}

The 'teamwork and leadership course' requires a great deal of careful and detailed planning. The time taken in this preparation cannot be underestimated. One of the other major issues is that of how students are assessed during the residential course. With 50 students it was necessary to have at least 4 members of staff present to supervise and assess the students. Even using this resource, assessment proved to be a very difficult task. Staff used checklists whilst observing students. The number of tasks observed was around 12, with groups of students being mixed for several tasks. This meant that staff were formulating opinions on all 50 students. Students were also asked to peer review their colleagues and fill in the checklists. It was therefore difficult to come to a clear judgement for each student as there were several hundred checklists filled in! This last year it was decided to take more staff and allocated 10 students per member of staff to act as facilitators of their learning and development. No summative assessment of the students took place over the residential weekend. Instead, students were asked to reflect upon their learning and skills development and write this up for assessment in their individual critical review. Members of staff helped the students to self-reflect during the weekend through careful support and guidance.

The International Product Development' module has evolved and become a success in generating excellent academic-industry collaboration. Students have developed a broad range of engineering, design and business skills. In addition, teamwork, communication and leadership skills have all been developed within the students. However, the 'video conferencing' project work also has its problems. One of the main problems this year has been the use of the video conferencing equipment via the internet using IP addresses. At each institution 'firewalls' are in place for security purposes. Using IP addresses therefore requires university central 'computer services' to release individual PC's so that video conferencing can take place. This was problematic and took several weeks to overcome. Using ISDN to link the video conferencing PC's was the better option as this did not require security release, since secure telephone lines are used. Also, the quality of video and audio is much better using an ISDN connection compared to using the internet. 


\section{Evaluation - External views}

Project funding from EPSRC to develop the Masters module in 'International Product Development' has led to the excellent partnerships between the university and industry, as students from small companies were able to attend the module at zero cost. Comments from the External Evaluator for EPSRC in February 2004 stated:-

“.......content and delivery was innovative and conforms to good practice. Features of particular merit comprise: embedding the unit within full-time and part-time MSc programmes; use of video conferencing, work based learning and development of the matching section; collaborative links with UK and overseas universities and interfaces with business students. The assessment classification (of the IPD module) is rated as 'outstanding'.

This view is further emphasised in comments from industrialists and the professional bodies, who have said that this is an excellent way for industry-university collaboration to evolve, and the ability to theme projects with the latest technical advances or with current global issues. Recently, the Institution of Mechanical Engineers within the UK has extended approval of all the postgraduate courses in Engineering at Sheffield Hallam that contain the group project, International Product Development, as 'Advanced Learning', so that students now graduating from these courses have the educational base to meet the requirements of UK-Spec and eventually become Chartered Engineers after gaining appropriate professional experience.

\section{Summary}

Overall the two courses described above have helped to develop communication, design and teamworking skills within engineering students. The students have further developed other interpersonal and professional skills. These types of activities excite and enthuse our student population with the challenges of engineering and also encourage them to accept greater responsibility for their own learning.

\section{Acknowledgements}

The authors would like to thank The Robert Gordon University, Aberdeen and Mercuria Business School, Helsinki, Finland for collaboration with Sheffield Hallam University on this reported work. Thanks also go to EPSRC and HEFCE (FDTL) for funding to support these developments.

\section{References}

1. Richardson, P., Business success, marketing and the engineer, Engineering Science and Education Journal (1997).

2. Brown, P., Scase, R., Universities and Employers Rhetoric and Reality in Smith, A., Webster, F., (Eds) The Post-modern University? Contested Visions of Higher Education in Society, Buckingham, SRHE and Open University Press (1997).

3. Hawkins, P., and Whiteway Research, Skills for Graduates in the 21st Century, Association of Graduate Recruiters, Cambridge (1995).

Proceedings of the 2005 American Society for Engineering Education Annual Conference \& Exposition Copyright (C) 2005, American Society for Engineering Education 
4. The Engineering Council, SARTOR 3 (1997).

5. The Engineering Council, The UK Standard for Engineering Professional Competence (UK-SPEC) (2004)

6. Robinson, IM, Bramhall, MD, Lawson, JS, "An Integrated Engineering Degree Programme (IEDP) for Industry". Presented at the "East - West Congress on Engineering Education", Jagiellonian University, Cracow, Poland, September 1991. Proceedings published by the Australasian Association for Engineering Education, Edited by Z.J. Pudlowski, pp 239-242 (1991).

7. Robinson, IM, Payne, RN, Jones, AF, Bramhall, MD, Lawson, JS, "Teamwork and Leadership Skills in Engineering Degrees", Proceedings of the ASEE Conference on Engineering Education, Vol. 2, pp 951956, Anaheim, USA (1995).

8. Belbin, M, Belbin questionnaire, http://www.belbin.co.uk/

9. Bramhall, MD, Allan, M, Harris, RG, Temple, BK "Student Teamworking within a Virtual Development Enterprise for Europe (VIDEEO)", presented at the $1^{\text {st }}$ Caledonian Centre for Engineering Education Conference on Life Long Learning for Engineers, Glasgow (1999).

10. Curtis, T, "Technology driven or market led, the new product development trap", Engineering Management Journal, pp 197-204 (2000).

11. Harris, RG, Bramhall, MD, Robinson, IM “Product Development: An Integrating Curriculum", Keynote Paper and Address, $2^{\text {nd }}$ Global Congress on Engineering Education, Conference proceedings pp 49-52, Wismar, Germany (2000).

\section{Biographical information}

\section{PROFESSOR MIKE BRAMHALL}

Professor Mike Bramhall holds a Chair in Engineering Education in the Faculty of Arts, Computing, Engineering and Sciences at Sheffield Hallam University and is the Faculty Head of Learning, Teaching \& Assessment. He is also the Associate Director of the UK Centre for Materials Education at Liverpool University. Mike is the Editor of the British Journal of Engineering Education.

\section{PROFESSOR IAN ROBINSON}

Professor Ian Robinson is the Head of Undergraduate Studies in the Faculty of Arts, Computing, Engineering and Sciences at Sheffield Hallam University and has a Chair in Engineering Education. Technically he specialises in electrical drives and power electronics, but spends much of his time working in the area of engineering pedagogy. Internationally he is a member of the International Liaison Group for Engineering Education.

\section{BOB HARRIS}

Bob Harris teaches engineering in the Faculty of Arts, Computing, Engineering and Sciences at Sheffield Hallam University. His research interests include the use of team working to develop student communication skills and the application of technology in engineering education. He has chaired an Engineering Education Conference and is a member of the Steering Committee of the UK's Higher Education Academy Engineering Subject Centre.

\section{DAVID HICK}

David Hick teaches engineering management in the Faculty of Arts, Computing, Engineering and Sciences at Sheffield Hallam University. After graduation in 1987 he completed an eight year commission as an Engineering Officer in the Royal Navy. During a five year period in industry he worked as a Materials and Manufacturing Manager. He is interested in the development of methods to improve project management abilities in engineers. 